\title{
Preparation and characterization of natural rubber/layered double hydroxide nanocomposites
}

\begin{abstract}
Nanocomposites of organo Zn-Al layered double hydroxide (LDH) with natural rubber (SMR CV60) were successfully synthesized and characterized. To prepare the nanocomposites, a hydrophilic Zn-Al layer double hydroxide (ZnAl LDH -NO3ī ) was first converted into the organophilic form by using dodecylsulphate ion (DS) as a guest in $\mathrm{Zn}$-Al layer double hydroxide (ZnAl LDH-DS). Intercalation of dodecylsulphate anion into the interlayer of LDH increased the surface area and the porosity of LDH. Nanocomposites of NR / ZnAl LDH-DS was then prepared by melt intercalation method using Haake internal mixer. The resulting compounds were then vulcanizated using the conventional method. X-Ray diffractogram the organophilic ZnAl-DS LDH shows the basal spacing of the ZnAl-LDH expands from 0.89 $\mathrm{nm}$ with nitrate as the intergallery anions to $2.53 \mathrm{~nm}$ due to the accommodation of DS surfactant anions. After the compounding with the natural rubber, the basal spacing of $\mathrm{ZnAl}$ LDH-DS in the composites is increased to 3.90 and $3.66 \mathrm{~nm}$ when the Zn-Al-LDH-DS contents are $1 \mathrm{phr}$ and $15 \mathrm{phr}$ respectively. TEM revealed the layered double hydroxide generally uniformly distributed in the rubber matrix. Further characterization indicates that the tensile strength of NR/ Zn-Al LDH-DS (nanocomposites) is higher than that of the NR/Zn-Al LDH-NO3ī (macrocomposites).
\end{abstract}

Keyword: Layered double hydroxide; Melt blending; Nanocomposites; Natural rubber 